\title{
COUPLING METHOD FOR INTERNAL NOZZLE FLOW AND THE SPRAY FORMATION FOR VISCOUS LIQUIDS
}

\author{
RATHESAN RAVENDRAN ${ }^{1, *}$, BENNY ENDELT ${ }^{2}$, JESPER DE CLAVILLE CHRISTIANSEN $^{2}$, \\ PETER JENSEN ${ }^{1}$, MARTIN THEILE $^{3}$, IBRAHIM NAJJAR $^{4}$ \\ ${ }^{1}$ Hans Jensen Lubricators, 9560 Hadsund, Denmark. \\ 2 Materials and Production, Aalborg University, 9220 Aalborg, Denmark. \\ ${ }^{3}$ FVTR GmbH, 18057 Rostock, Denmark. \\ ${ }^{4}$ University of Rostock, 18057 Rostock, Denmark.
}

\begin{abstract}
Understanding the disturbances introduced by cavitation inside spray nozzles is important, when simulating the spray formation of highly viscous liquids. In this paper, a new model for cavitation-induced primary break-up is proposed, which is able to map the influence of cavitating nozzle flow on spray formation. Detailed experimental and numerical investigations of the viscous nozzle flow have been performed in order to develop an improved primary break-up model [1]. The proposed model describes the transition from the flow inside the nozzle, modelled using a homogeneous equilibrium model (HEM) method, to the first primary droplets modelled using a Eulerian-Lagrangian method. Thus, providing the boundary conditions for the calculation of the secondary break-up and spray formation. The nozzle exit is divided into a definite number of patches. Liquid momentum and vapor volume fraction from each patch are used to initialize the primary droplets. The model has been implemented in the open-source CFD software package OpenFOAM and validation has been done using high-speed shadow graphic imaging. The simulated spray tip penetration and spray cone angle at the near-nozzle region show a good agreement with the experiment results.

Keywords: cavitation, numerical simulation, OpenFOAM, primary break-up, Spray formation, viscous liquids.
\end{abstract}

\section{INTRODUCTION}

Cavitation inside spray nozzles have a great importance on the break-up of liquid jets [2] [4]. In simple pressure spray systems, liquid jet does not atomize greatly when disturbances caused by cavitation are not present [5], [6]. This is especially true for viscous liquids, which are difficult to atomize unless high fluid pressure is applied [7]. Cavitation occurs when the local pressure of the liquid drops below its vapor pressure [8], and thereby forming vapor cavities inside the liquid. The collapse of these cavities introduce disturbances to the liquid, which leads to faster break-up and greater atomization of the exiting jet [9]-[11]. Several factors influence the formation of cavitation as, e.g. sharp inlet orifices, needle lift, curvature of the inlet edge, liquid properties, and system pressure [6], [12]-[14]. Ravendran et al. [1] investigated the cavitation-induced atomization of viscous liquids using a transparent spray nozzle. The fluid viscosity was $0.05 \mathrm{~Pa} \cdot \mathrm{s}$ and the fluid pressure was $4 \mathrm{MPa}$. The study showed that non-axial injection conditions lead to a swirling liquid flow inside the nozzle. Thus, leading to the development of cavitation strings in the core of the liquid vortices. The degree of atomization increases significantly, when these cavitation strings extend to the exit of the nozzle. However, when the cavitation bubbles collapse in the nozzle volume, the viscous liquid is able to stabilize the disturbances introduced by cavitation.

For many decades, cavitation inside spray nozzles has been studied in order to determine the effects on droplet break-up; however, the phenomenon is still poorly understood. A better understanding of cavitation demands detailed information, on the flow inside the nozzle and the subsequent spray, which is difficult to observe experimentally. This information can be 
obtained from a properly validated computational spray model. Several methods exist and are implemented in commercial CFD-codes for simulating the spray formation using the Lagrangian method as, e.g. Taylor Analogy, Kelvin-Helmholtz and Rayleigh-Taylor break-up [3]. However, these models need sub-models to describe the transition from the nozzle flow to the primary droplet, as illustrated in Fig. 1. This coupling has been the focus of several authors, as the transition between the nozzle flow and spray formation is very complicated [15]-[17]. The majority of current coupling models employ simplified boundary conditions at the nozzle exit, as an indirect coupling to the primary droplets. Such methods often dampen or lead to the loss of the nozzle flow characteristic, which is the drawback of the EulerianLagrangian approach for simulating sprays.

The simplest method for introducing the Lagrangian droplets is by the blob-method. The blob method is based on the assumption that detailed description of the atomization and drop break-up processes within the dense spray near the nozzle is not required. The Lagrangian droplets are therefore initiated by spherical droplets with a diameter equal to the nozzle hole diameter, which means the break-up occurs due to secondary aerodynamic-induced break-up. Cavitation-induced break-up models have been developed by some researches in the recent years. The proposed break-up models are either based on one dimensional or phenomenological models of the cavitation inside the nozzle volume [18][20]. Arcoumanis et al. [21] included cavitation in the primary break-up by calculating an effective hole diameter (the total area of the nozzle aperture occupied by cavitation) in order to determine the initial droplet diameter of droplets. Nishimura and Assanis [22] proposed a cavitation and turbulence-induced primary break-up model for diesel sprays. This model determines the bubble dynamics inside the injector and transfers collapse energy to turbulent kinetic energy, which is then transformed to an additional break-up force included in the secondary break-up [3].

Baumgarten et al. [15] proposed a cavitation-induced break-up model based on experimental investigations of a quasi-stationary spray. The model defines two different zones in the nozzle volume. The first zone contains the liquid core of the jet, while the second zone consists of a mixture of cavitation bubbles and liquid ligaments. Break-up of the different zones is treated separately. The energy from the collapse of cavitation bubbles is transferred both to the outer surface and break-up of the mixture zone, as well as to the interface between the two zones to increase turbulent energy of liquid core.

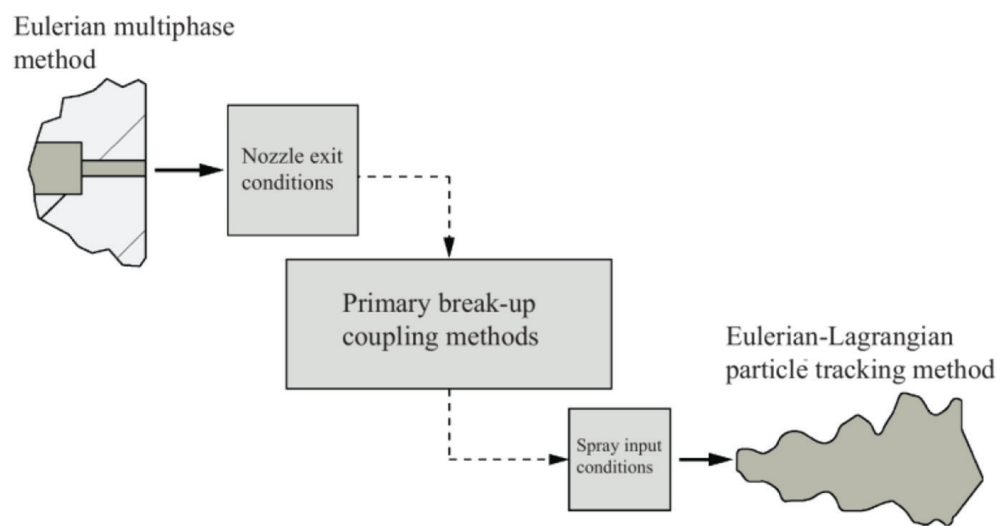

Figure 1: Illustration of the numerical simulation approach used in this study. 
The present coupling models are related to low-viscous liquids such as diesel fuels. This means that the models are based on assumptions, which may not valid for cavitation-induced break-up of viscous liquids. This leads to the objective of this study.

In this paper, a method for coupling the internal viscous flow and the subsequent spray is proposed. The study is a continuation of the work presented in Ref. [23]. The purpose of the new primary break-up model is to describe the transition from the flow inside the nozzle to the first primary droplets. Thus, providing all starting conditions for the calculation of secondary break-up and spray formation. The input data for the new model are based on the detailed numerical investigations of the nozzle flow performed in Ref. [1]. High-speed shadow graphic imaging has been used to validate the proposed model in spray tip penetration and spray cone angle at the near-nozzle region.

\section{NUMERICAL SIMULATION APPROACH}

The simulation approach is divided in two steps, as shown in Fig. 2. Firstly, the simulation of the liquid flow and cavitation inside the nozzle is performed using multiphase approach with a Schnerr-Saur cavitation model. Secondly, the simulation of the spray formation is performed using an Eulerian-Lagrangian approach using a KHRT secondary break-up model. The two simulations are connected using a coupling model, which translates the flow inside the nozzle to the first primary droplets at the nozzle exit. The focus of the following section is to describe the coupling model. Simulation of the cavitating nozzle flow is described in detail in Ref. [1] and the KHRT-model is for example documented in Ref. [16], [24].

\subsection{The coupling model}

The purpose of the coupling model is to initiate the primary droplets using the nozzle exit conditions. The nozzle exit is therefore separated into a defined number of boundary patches, from which liquid velocity $(u)$ and degree of cavitation $(\alpha)$ are used to calculate the diameter of the primary droplet $\left(D_{i}\right)$, mass flow rate $\left(\dot{m}_{i}\right)$, and spray angle $\left(\varphi_{i}\right)$ at each patch $(i)$.

The location of each patch is randomly selected, in order to suppress geometrical effects when introducing a defined boundary grid. This approach makes the model flexible and applicable for different nozzle geometries. However, as patches are allowed to overlap and exceed the diameter of the nozzle, minor errors in spray angle are expected.

The first droplets at the nozzle exit are introduced using the so-called blob-method, where the assumption is that the dense spray near the nozzle can be represented by spherical

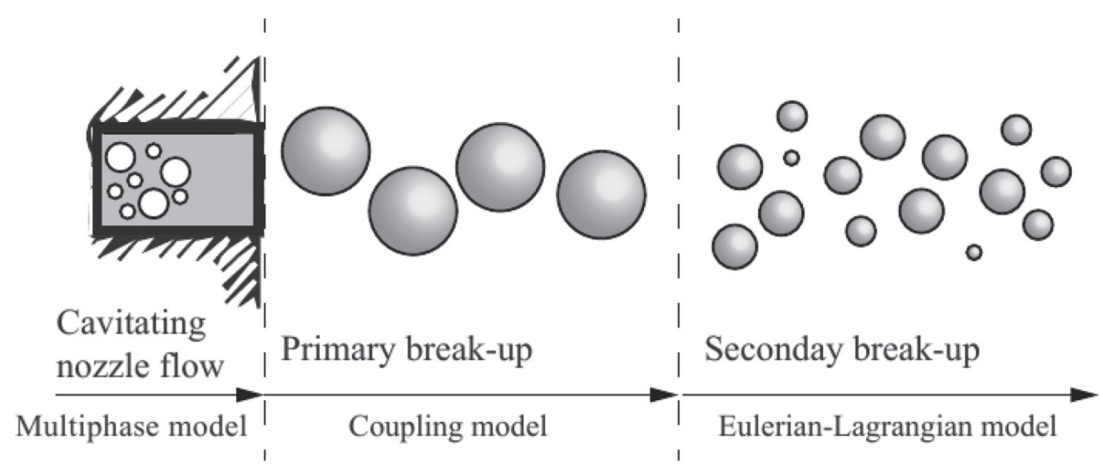

Figure 2: Overview of the numerical simulation approach. 
droplets with uniform size. The diameter of these droplets equals the nozzle hole diameter. The number of the droplets injected per unit time is determined from the mass flow rate. The mass flow rate of the primary droplets is calculated as:

$$
\dot{m}_{i}(t)=\rho_{l} \cdot A_{\text {patch }} \cdot u_{i}(t),
$$

where $\rho_{l}$ is the liquid density, $A_{\text {patch }}$ is the area of the selected patch, $u_{i}(t)$ is the velocity of the liquid composed of the three components in $x, y$, and $z$-direction.

The direction of the droplets leaving the nozzle exit is defined using the spray angle. These parameters are highly influenced by the degree of cavitation at the nozzle exit, as bursting of cavitation bubbles leads to increased spray angle. The degree of cavitation is expressed in terms of vapor volume fraction $\left(\alpha_{i}\right)$, which is directly extracted from the internal flow simulations. The vapor volume fraction is described by a number from 0 to 1 , for $\alpha_{i}<1$ the patch cavitates.

$$
\varphi_{i}=\left\{\begin{array}{c}
0 \alpha_{i}=1 \\
\cos ^{-1}\left(\frac{u_{i, \text { plane }} \cdot u_{i, y}}{\left\|u_{i, \text { plane }}\right\| \cdot\left\|u_{i, y}\right\|}\right) \alpha_{i}<1
\end{array},\right.
$$

where $u_{i, y}$ is the velocity vector of the liquid perpendicular to the nozzle exit and is defined by $u_{i, p l a n e}=u_{i, x}^{2}+u_{i, z}^{2}$ and describes the velocity components parallel to the nozzle exit.

\subsection{Computational grid and boundary conditions}

The boundary conditions were set according to the experimental conditions with a nozzle inlet pressure $P_{\text {inlet }}=4.0 \mathrm{MPa}$ and outlet pressure $P_{\text {outlet }}$ equal to the ambient pressure at $0.1 \mathrm{MPa}$. The movement of the injector needle is taken into account using an exponential ramp up of the inlet pressure corresponding to the position of the needle.

The numerical simulation of the internal flow and the spray formation is performed using OpenFOAM 3.1. The coupling routine is implemented in a MATLAB code. For all calculation a parcel injection rate of $2 \cdot 10^{6}$ parcels per second is used, which is considered to be sufficient for reliable results.

The computational grid is a $10 \times 10 \times 300 \mathrm{~mm}$ rectangular box with a mesh grid size of $1 \mathrm{~mm}$. The mesh size is the same in all directions and kept unchanged in all of the simulations. It is well known that the mesh can play an important role when simulating sprays with the Lagrangian approach. Mesh resolution is more critical in high pressure and high density spray simulations, since liquid volume is considered small compared to the gas phase volume [18]. The simulations are performed with an adjustable time step limited by the Courant number. The Courant number is set to 0.5 and the initial time step $\Delta \mathrm{t}$ is set to $10^{-7} \mathrm{~s}$.

\section{EXPERIMENTAL SETUP}

A schematic overview of the test setup is shown in Fig. 3. The setup consists of a HJ Lubtronic system from Hans Jensen Lubricators A/S (1), which delivers $50 \mathrm{mg}$ lubrication oil per injection to a heated HJ-SIP injection valve (2). The lubrication oil is injected in to a chamber (3) with ambient atmospheric conditions. To actuate the lubricator, $7 \mathrm{MPa}$ hydraulic pressure is supplied from a standard pump station (4). Fresh lubrication oil to the lubricator is delivered from a heated reservoir (5). The internal geometry of the nozzle head in the injection valve is shown in Fig. 4. The opening pressure of the injection valve is $4.0 \mathrm{MPa}$. 




Figure 3: The layout of the experimental setup.

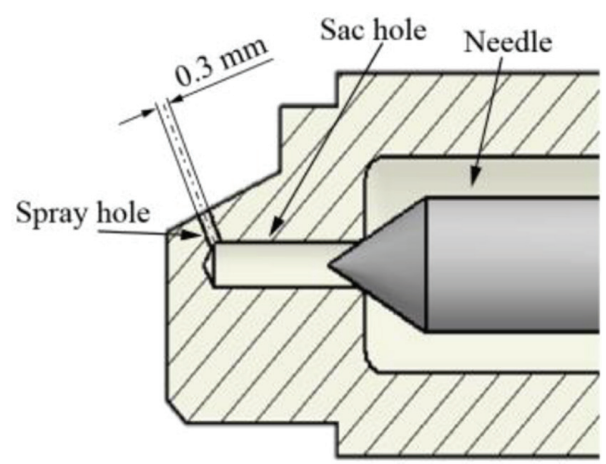

Figure 4: The internal geometry of the HJ-SIP spray injection valve.
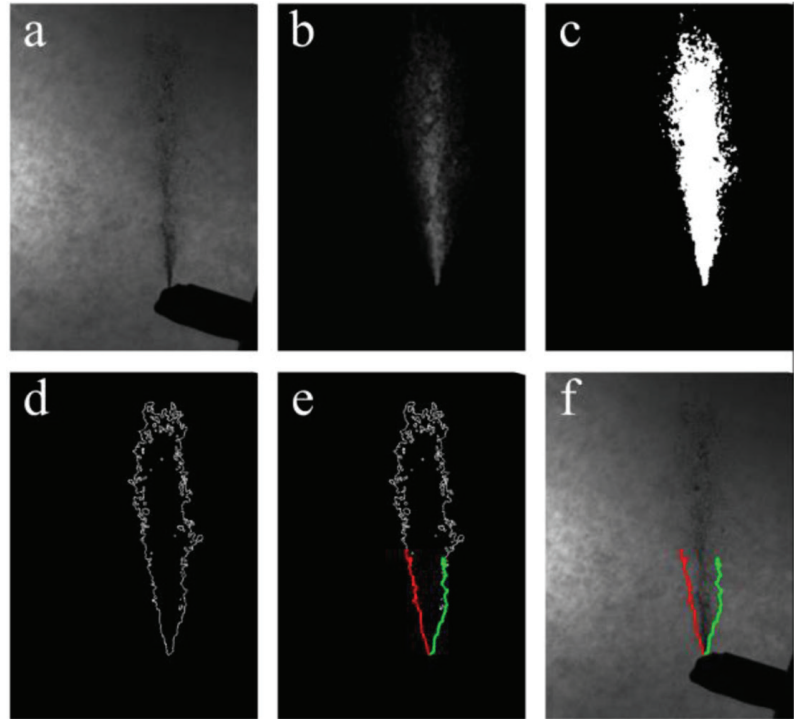

Figure 5: The image processing algorithm. (a) Unprocessed original image. (b) Background subtraction and Contrast stretching (c) Thresholding. (d) Edge detection. (e) Curve fitting. (f) Processed final image. 
The high-speed camera (6) and illumination source (7) are set up at either side of the spray in order to capture the images using the shadowgraphic method, where the spray is visualised as dark in front of an illuminated background. A control system (8) is developed in order to regulate the temperature on the lubrication oil, and to initialise both the high-speed camera and the lubricator.

The high-speed camera used in this study is a Photron Fastcam SA5 and a 1000W LED lamp is used as the illumination source. Images are taken with a frame rate of $15000 \mathrm{fps}$ with a shutter speed of $1 / 171000$. Both the high-speed camera and the lubricator are controlled by a computer in order to synchronize the images.

Each image is processed using a custom algorithm in MATLAB, which detects the spray boundary and computes the spray tip penetration and cone angle. The algorithm consists of several image-processing steps in order to distinguish the spray from the background sufficiently. These image processing steps are shown in Fig. 5.

\section{MATERIALS}

The commercial lubrication oil Mobilgard 570 is used for the spray investigations. The material properties for this oil are presented in Table 1 . The properties that are highly affected by temperature change are expressed as a function.

Table 1: Lubrication oil properties used in this study. In the following equations $R$ is the ideal gas constant, and $T$ is the temperature of the lubrication oil expressed in Celsius.

\begin{tabular}{|c|c|c|}
\hline Oil property & Value & Reference \\
\hline Vapor pressure & $\begin{array}{l}P_{v}(T)=10 \cdot e^{(A \cdot T-B) /((20.0 \cdot T+C)) \cdot \mathrm{R}} \mathrm{kPa} \\
\text { The dimensionless constants are } \mathrm{A}=1094 \\
\mathrm{~B}=3.458 \cdot 10^{5}, \text { and } \mathrm{C}=5463.0\end{array}$ & $\begin{array}{l}\text { Derived using the } \\
\text { Clausius-Clapeyron } \\
\text { equation }\end{array}$ \\
\hline Liquid density & $\rho_{l}(T)=0.6087 \cdot T+943.97 \mathrm{~kg} / \mathrm{m}^{3}$ & Measured \\
\hline Liquid viscosity & $\mu_{l}(T)=0.00610 \cdot e^{1246 /(\mathrm{R} \cdot T)} \mathrm{Pa} \cdot \mathrm{s}$ & {$[25]$} \\
\hline Vapor density & $\rho_{v}=16.05 \mathrm{~kg} \cdot \mathrm{m}^{-3}$ & [26] \\
\hline Vapor viscosity & $\mu_{v}=11.58 \mu \mathrm{Pa} \cdot \mathrm{s}$ & {$[26]$} \\
\hline
\end{tabular}

\section{VALIDATION AND RESULTS}

In order to validate the proposed spray model, four injection conditions have been studied. The only difference is the temperature of the lubrication oil; Case 1: $T_{\mathrm{L}}=100^{\circ} \mathrm{C}$, Case 2: $T_{\mathrm{L}}=60,80$, and $120^{\circ} \mathrm{C}$. Case 1 is used to compare the model behavior, whereas Case 2 is used evaluate the performance of different injector conditions. As shown in Fig. 6, the temperature of the liquid has a significant role on the degree of cavitation and the flow inside the spray nozzle, due to the change in liquid viscosity and vapor pressure.

The nozzle exit conditions for the different injection cases, shown in Figs 7 and 8, are used for the spray simulations. Liquid momentum and vapor volume fraction from each patch are used to initialize the primary droplets. The velocity at the nozzle exit is shown in Fig. 7, where 


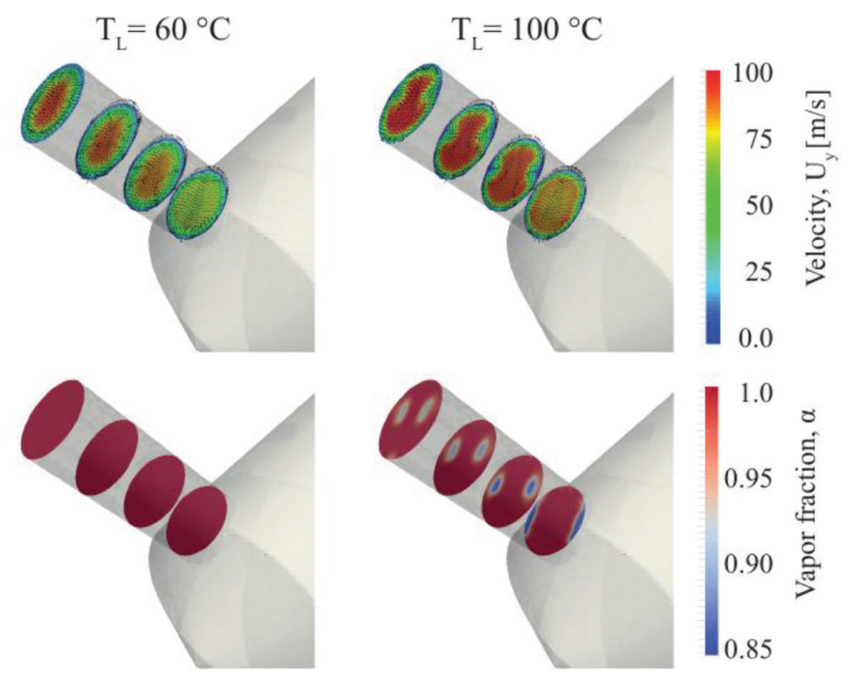

Figure 6: The numerical results of the internal nozzle flow showing liquid velocity and vapor volume fraction throughout the spray hole.

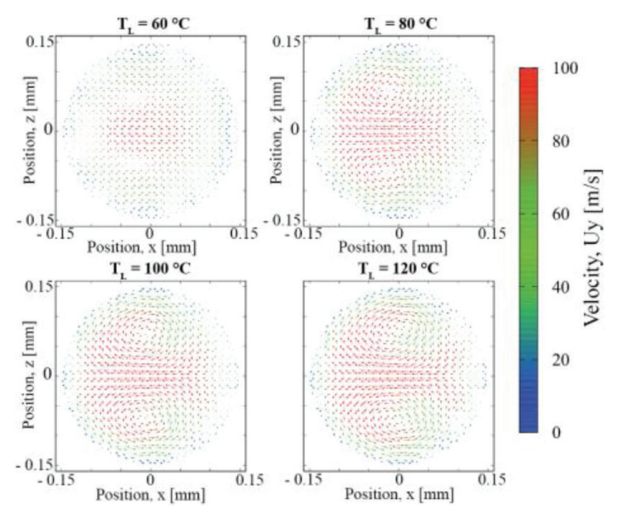

Figure 7: The numerical results for the studied injection cases showing the velocity at the nozzle exit.

the fringe level indicates the velocity in $y$-direction $\left(\mathrm{U}_{\mathrm{y}}\right)$ and the vector field represents velocity components in the $x z$-plane $\left(\mathrm{U}_{\mathrm{x}}\right.$ and $\left.\mathrm{U}_{\mathrm{z}}\right)$. It is seen that the swirling flow is prominent at higher temperatures, and at low temperatures the flow is non-swirling and axisymmetric. The swirling flow leads to the cavitation strings inside the core of the liquid vortices. Figure 8 shows that a higher degree of cavitation is achieved when the swirling flow is more prominent. A thorough description of the internal flow and the behavior of vortex cavitation can be found in Ref. [1].

\subsection{Experimental results and model validation}

Figure 9 shows the computational and experimental results of the spray formation for injection Case 1. The numerical simulations are performed using $N_{P}=100$, which is the number 

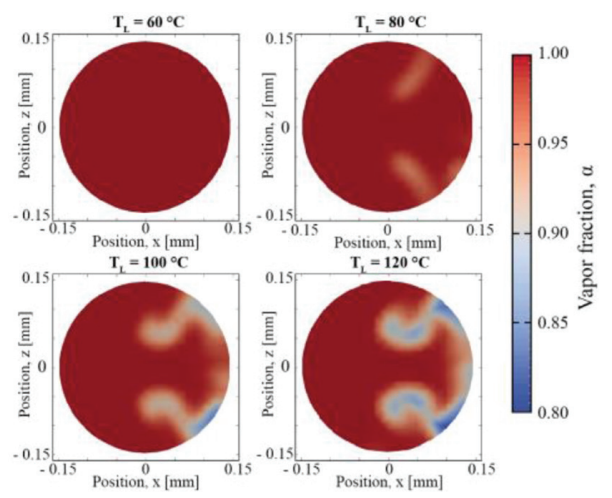

Figure 8: The numerical results for the studied injection cases showing the vapor fraction volume at the nozzle exit.



Figure 9: Spray formation due to cavitation-induced break-up (comparison between experiment and numerical simulation). The temperature of the injected liquid is $T_{\mathrm{L}}=100^{\circ} \mathrm{C}$. The numerical simulations are performed using $N_{P}=100$.

of selected patches. The importance of this model constant is discussed in section 5.2. The simulation results show a dense liquid core in the center of the spray, and smaller dispersed ligaments away from the center. These observations agree with the experimental observations. It is also important to highlight that the proposed model is capable of predicting the spray structure and asymmetrical shape apart from the spray tip penetration.

The spray tip penetration $\mathrm{L}$ and cone angle $\theta$ is shown in Fig. 10. The figure shows that there is a minor difference between the simulated and measured spray penetration. The simulated spray penetrates faster through the ambient atmosphere compared to the measured spray. There is an error of $8.2 \%$ at $t=1.8 \mathrm{~ms}$. It is expected, that this error relates to the interaction between the droplets and the surrounding gas. This is why this error can be minimized by adjusting the model constants for the secondary break-up, e.g. by enhancing the break-up process, meaning that smaller droplets will penetrate slower than larger droplets [15]. 




a) Spray tip penetration

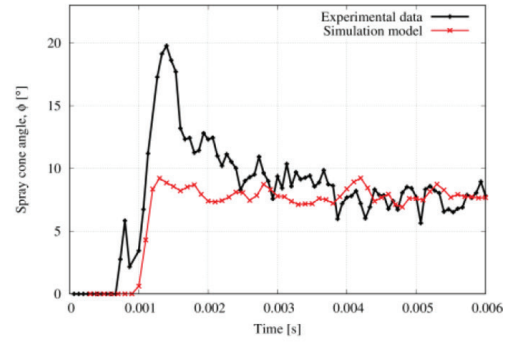

b) Spray cone angle

Figure 10: Comparison of the spray penetration and angle (Case 1).

Comparison of the computed and measured spray cone angle is shown in Fig. 10b. The measured spray cone angle is large at the beginning of the injection. As soon as the penetration increases, the resulting spray cone angle becomes smaller. The initial spray structure depends on the speed of the needle, as a slow opening results in larger spray angles, whereas a fast opening results in smaller angles. Even though the needle motion is considered in the model with a pressure boundary, the prediction of the initial spray angle is not accurate. However, a good agreement between the measured and computed steady-state spray cone angle is observed.

The experimental images in Fig. 9 show an asymmetrical structure of the spray. This asymmetry occurs due to the asymmetrical nozzle flow and especially due to the concentration of cavitation at one side of the spray hole. Figure 11 shows the calculated angle for each half of the spray extracted. It is shown, that the side where cavitation is prominent leads to a higher spray angle compared to the side with less cavitation. The average of $\varphi_{1}=4.27^{\circ}$ and the average of $\varphi_{2}=3.52^{\circ}$, which leads to a difference of $21.3 \%$.

\subsection{Influence of random selected patches}

In the following section the influence of the number of random selected patches $N_{P}$ is analyzed. Figure 12 shows the spray penetration and spray cone angle for different values of $N_{P}$.



Figure 11: The asymmetrical structure of the spray represented by $\varphi_{1}$ and $\varphi_{2}$, which is the angle from the spray center to the spray contour. The angles are shown in Figure 10b. The average of $\varphi_{1}=4.27^{\circ}$ and the average of $\varphi_{2}=3.52^{\circ}$. 


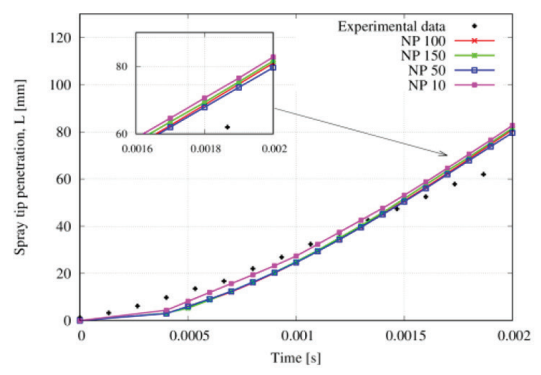

a) Spray tip penetration

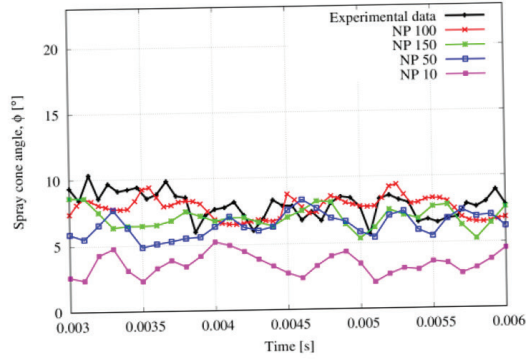

b) Spray cone angle

Figure 12: The influence of the number of randomly selected measurement points $N_{P}$ for the proposed spray model.

The value of $N_{P}$ depends on the area of the nozzle hole exit. The larger the area the more measurement points are needed in order to ensure a sufficient prediction of the spray formation. However, this also increases the computational time. Figure 12a shows that the penetration is not as influenced by $N_{P}$ as the spray angle. Furthermore it can be concluded that $N_{P}$ must be larger than 50 to ensure a sufficient prediction, when the diameter of the nozzle hole exit is $0.3 \mathrm{~mm}$.

\subsection{Influence of liquid temperature}

Figure 13 shows the computational results of the spray formation for the three injection conditions in Case 2. There is a good agreement between the computed and the measured spray cone angle. There is no break-up at $T_{L}=60^{\circ} \mathrm{C}$, due to no cavitation at the end of the nozzle exit. This leads to a jet with a small spray cone angle, which is correctly predicted by the proposed model. As temperature increases the degree of cavitation increases, which leads to higher spray cone angles.

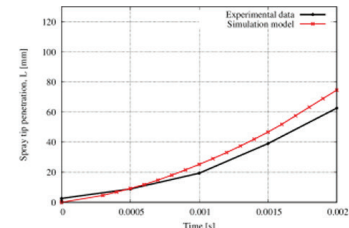

a) Spray penetration $T_{\mathrm{L}}=60^{\circ} \mathrm{C}$.

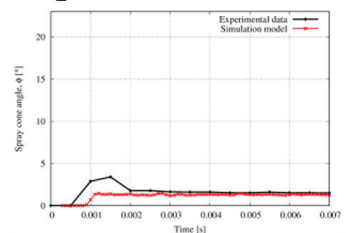

d) Spray angle $T_{\mathrm{L}}=60^{\circ} \mathrm{C}$.

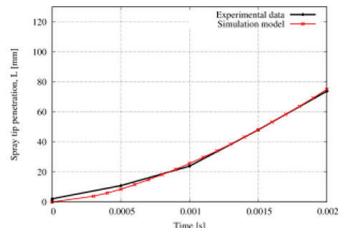

b) Spray penetration



e) Spray angle $T_{\mathrm{L}}=80^{\circ} \mathrm{C}$.



c) Spray penetration $T_{\mathrm{L}}=120^{\circ} \mathrm{C}$.

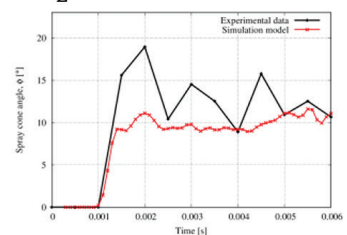

f) Spray angle $T_{\mathrm{L}}=120^{\circ} \mathrm{C}$.

Figure 13: Comparison of spray penetration and spray angle of different temperatures. 
Regarding the spray tip penetration, there is only a good agreement between the computed and the experimental spray tip penetration at $T_{L}=80^{\circ} \mathrm{C}$. The model overestimates the penetration length at $T_{L}=60^{\circ} \mathrm{C}$ and $120^{\circ} \mathrm{C}$. This overestimation is considered to be attributed to the coupling between the proposed model and the spray droplets. In this study the blobmethod has been used, which assumes that the size of the droplets leaving the nozzle is the size of the nozzle hole. However, this consideration is not sufficient when having cavitation-induced break-up. Droplet size and droplet behavior in the surrounding gas plays an important role, the bigger droplets result in faster penetration compared to smaller droplets. Therefore, a more accurate coupling between the droplet size and nozzle flow is needed in order to minimize the inaccuracy.

\section{CONCLUSION}

A new approach for modelling cavitation-induced break-up for viscous liquids has been presented in this paper. The proposed model describes the transition from the flow inside the nozzle, modelled using a homogenous equilibrium model (HEM) method, to the first primary droplets modelled using a Eulerian-Lagrangian method. Thus, providing all starting conditions for the calculation of the secondary break-up and spray formation.

The validation of the presented approach has been done by comparison of spray structure, spray tip penetration and spray cone angle between experiments and simulations. The results showed that the simulations have the ability to reproduce the experimental trends of viscous sprays. Especially, the influence of cavitation on the spray structure is well reproduced with the presented modelling approach. Higher degrees of cavitation at the nozzle exit leads to increased droplet break-up and spray cone angle.

In order to increase the accuracy of the presented model, a more detailed coupling between nozzle flow and droplet size is needed. However, this has not been the scope of this paper.

\section{REFERENCES}

[1] Ravendran, R., deClaville Christiansen, J., Jensen, P. \& Endelt, B., Numerical study of cavitation of high-viscous liquid spray systems. ILASS Americas 28th Annual Conference on Liquid Atomization and Spray Systems, pp. 1-12, May 2016.

[2] Fansler, T.D. \& Parrish, S.E., Spray measurement technology: a review. Measurement Science and Technology, 26(1), p. 012002, 2015.

[3] Le Moyne, L., Trends in atomization theory. International Journal of Spray and Combustion Dynamics, 2(1), pp. 49-84, 2010.

[4] Sou, A., Hosokawa, S. \& Tomiyama, A., Effects of cavitation in a nozzle on liquid jet atomization. International Journal of Heat and Mass Transfer, 50(17-18), pp. 35753582, 2007.

[5] Dabiri, S., Sirignano, W.A. \& Joseph, D.D., Cavitation in an orifice flow. Physics of Fluids, 19(7), p. 072112, 2007.

[6] Dumouchel, C., On the experimental investigation on primary atomization of liquid streams. Experiments in Fluids, 45(3), pp. 371-422, 2008.

[7] Tamaki, N. \& Shimizu, M., Enhancement of atomization of high-viscous liquid jet by pressure atomized nozzle. ILASS-Europe 2002, 2002.

[8] Franc, J.-P. \& Michel, J.-M., Fundamentals of Cavitation, Springer Science + Business Media, Inc., 2006.

[9] Baumgarten, C., Stegemann, J. \& Merker, G., A new model for cavitation induced primary break-up of diesel sprays. ILASS-Europe 2002, 2002. 
[10] Bergwerk, W., Flow pattern in diesel nozzle spray hole. Proceedings of the Institution of Mechanical Engineers, 173(1), pp. 655-660, June 1959.

[11] Dumouchel, C., Leboucher, N. \& Lisiecki, D., Cavitation and primary atomization in real injectors at low injection pressure condition. Experiments in Fluids, 54(6), pp. 1-17, 2013.

[12] Jollet, S., Hansen, H., Bitner, K., Niemeyer, D. \& Dinkelacker, F., Experimental and numerical investigations of 90 micrometer real-size transparent nozzles with high pressure conditions. ILASS-Europe 2014, 2014.

[13] Pratama, R.H., Sou, A., Wada, Y. \& Yokohata, H., Cavitation in mini-sac nozzle and injected liquid jet. ICLASS-2015, 2015.

[14] Andriotis, A., Gavaises, M. \& Arcoumanis, C., Vortex flow and cavitation in diesel injector nozzles. Journal of Fluid Mechanics, 610, pp. 195-215, 2008.

[15] Baumgarten, C., Mixture Formation in Internal Combustion Engine, Springer Berlin Heidelberg, 2006.

[16] Mohan, B., Yang, W. \& Chou, S., Cavitation in injector nozzle holes - A parametric study. Engineering Applications of Computational Fluid Mechanics, 8(1), pp. 70-81, January 2014.

[17] Yu, H., Goldsworthy, L., Brandner, P. \& Garaniya, V., Modelling of in-nozzle cavitation and early spray breakup using a multiphase volume of fluid method. In 20th Australasian Fluid Mechanics Conference Perth, 2016.

[18] Mohan, B., Yang, W. \& Chou, S.K., Development of an accurate cavitation coupled spray model for diesel engine simulation. Energy Conversion and Management, 77, pp. 269-277, 2014.

[19] Santos, F.D. \& Moyne, L.L., Spray atomization models in engine applications, from correlations to direct numerical simulations. Oil \& Gas Science and Technology-Revue d'IFP Energies Nouvelles, 66(5), pp. 801-822, 2011.

[20] Herrmann, M. On simulating primary atomization using the refined level set grid method. Atomization and Sprays, 21(4), pp. 283-301, 2011.

[21] Arcoumanis, C., Gavaises, M. \& French, B., Effect of fuel injection processes on the structure of diesel sprays. SAE Technical Paper 970799, 1997.

[22] Nishimura, A. \& Assanis, D.N., A model for primary diesel fuel atomization based on cavitation bubble collapse energy. ICLASS 2000, pp. 1249-1256, 2000.

[23] Ravendran, R., Endelt, B., deClaville Christiansen, J. \& Jensen, P., Model for cavitation induced primary break-up of viscous liquid sprays. In Computational \& Experimental Methods in Multiphase and Complex Flow, 2017.

[24] Reitz, R.D. \& Beale, J.C., Modeling spray atomization with the Kelvin-Helmholtz/ Rayleigh-Taylor Hybrid model. Atomization and Sprays, 9(6), pp. 623-650, 1999.

[25] Ravendran, R., deClaville Christiansen, J., Endelt, B., Jensen, E.A. \& Jensen, P., Rheological behavior of lubrication oils used in two-stroke marine engines. Industrial Lubrication and Tribology, 69(5), pp. 750-753, 2017.

[26] Assael, M.J., Dalaouti, N.K. \& Vesovic, V., Viscosity of natural-gas mixtures: Measurements and prediction. International Journal of Thermophysics, 22(1), pp. 61-71, 2001. 